\title{
O ENSINO DE HISTÓRIA NO CURSO TÉCNICO INTEGRADO DE TURISMO - CEFETRN/IFRN - CAMPUS NATAL/CENTRAL (2005-2011)
}

\author{
A. C. S. LIMA ${ }^{1^{*}}$ e O. M. MEDEIROS NETA ${ }^{2}$ \\ ${ }^{1}$ Instituto Federal de Educação, Ciência e Tecnologia do Rio Grande do Norte \\ ${ }^{2}$ Universidade Federal do Rio Grande do Norte \\ aline.prof.his@gmail.com
}

Artigo submetido em julho/2015 e aceito em dezembro/2015

DOI: $10.15628 /$ rbept.2015.3217

\section{RESUMO}

O presente estudo busca compreender o espaço que o Ensino de História ocupava no currículo do Curso Técnico de Nível Médio Integrado de Turismo, do CEFETRN/IFRN - Campus Natal/Central (2005-2011). Realizamos um levantamento bibliográfico sobre a produção do conhecimento na área de Ensino de história, com ênfase no diálogo com trabalhos de Circe Bittencourt, Geraldo Horn e Geyso Germinari. No que concerne a relação Educação/trabalho seguimos os princípios definidos por Antonio Gramsci, revisitando também as concepções de Ensino Médio Integrado e Educação Profissional mais contemporâneas, bem como as prescrições legais para essa modalidade, o Decreto 5.154/2004 e o Plano de
Curso de Turismo. Entrevistamos docentes de História que atuaram no referido curso, para entendermos as concepções de Ensino de História e as práticas pedagógicas desenvolvidas nos liames entre EMI e Ensino de História. Percebemos que embora haja avanços no PPC de Turismo (2005), e algumas possibilidades do exercício da história temática e de uma aproximação mais eficaz entre história e trabalho, ainda prevalece a noção de linearidade e eurocentrismo na organização curricular, dificultando a proposta de integração inerente ao EMI. No que concerne às práticas dos professores, afirmamos que não havia um modelo de Ensino de História, mas múltiplas práticas e concepções.

PALAVRAS-CHAVE: Ensino de História, Ensino Médio Integrado, Currículo, Práticas Pedagógicas.

\section{THE HISTORY TEACHING IN THE INTEGRATED TOURISM TECHNICAL COURSE - CEFETN/IFRN - NATAL CAMPUS/CENTRAL (2005-2011)}

\begin{abstract}
The current study seek to understand the space that the history teaching held in the integrated tourism technical course, middle level, of the CEFETRN/IFRN Natal campus/Central (2005/2011). We conduct a bibliographic survey about the production of knowledge on history teaching area, with emphasis in the dialogue on jobs of Circe Bittencourt, Geraldo Horn and Geyso Germinari. As regards to relation education/work, we follow the principles defined by Antonio Gramsci, also revisiting the conceptions of integrated high school and professional education contemporary, as well as the legal requirements for this type, the decree 5.154/2004 and the plan of tourism course. We interviewed history
\end{abstract}

teachers who acted in that course, to understand the conceptions of history teaching and the pedagogical practices developed in bonds between EMI and history teaching. We realized that although there are advances in tourism PPC (2005), and some possibilities of the exercise of thematic history and a more effective approach between history and work, still prevails the linearity and eurocentrism notion in curricular organization, difficulting the integration proposal, inherent to EMI. Concerning to teachers practices, we affirm that there was not a model of history teaching, but multiple practices and conceptions.

KEYWORDS: History Teaching, Integrated High School, Curriculum, Pedagogical Practices. 


\title{
1 INTRODUÇÃO
}

\begin{abstract}
"O momento atual tem propiciado a introdução de algumas reflexões sobre a necessidade urgente do ofício do historiador e do professor de História no sentido de evitar a amnésia da sociedade atual marcadas por incertezas e perspectivas indefinidas."
\end{abstract}

Circe Bittencourt

A proposta de um ensino que dialoga com o mundo do trabalho é um caminho para a formação humana integral. E por ser o trabalho condição sine qua non da natureza humana, a escola precisa inseri-lo como parte integrante de seu currículo, sobretudo no Ensino Médio. Mas como a inserção do trabalho como categoria educacional viria a ocorrer? Qual o lugar da História nesse cenário?

Legalmente, o Ensino Médio Integrado é uma proposta de formação que abrange as dimensões do trabalho, ciência, tecnologia e cultura, dialogando com os saberes gerais e da formação para o mundo do trabalho. Essa modalidade de ensino legitimou-se por meio do Decreto n. $5.154 / 04$.

A partir dessas discussões, buscamos compreender o lugar que a História assumia no currículo do Curso Técnico Integrado de Turismo entre os anos de 2005 a 2011. Partimos da premissa de que há um currículo formal, que se trata do conjunto de prescrições oriundas das diretrizes curriculares, produzidas no âmbito nacional e local com base em documentos oficiais, mas há também um currículo praticado pelos professores que podem seguir as prescrições legais ou não.

\section{ENSINO DE HISTÓRIA E CURRÍCULO}

Quando falamos em EMI e ensino de história precisamos questionar: que sociedade queremos? Aquela que prima pela emancipação ou a que esconde a exclusão por trás de um discurso mercadológico de inclusão e igualdade social? Para refletir sobre essas questões partimos da compreensão dos sentidos do Ensino Médio Integrado (EMI), tomando por base a ideia da Marise Ramos que afirma:

Compreender a relação indissociável entre trabalho, ciência e cultura significa compreender o trabalho como princípio educativo, o que não se confunde com o "aprender fazendo", nem é sinônimo de formar para o exercício do trabalho. Considerar o trabalho como princípio educativo equivale dizer que o ser humano é produtor de sua realidade e, por isto, se apropria dela e pode transformá-la. Equivale dizer, ainda, que nós somos sujeitos de nossa história e de nossa realidade. Em síntese, o trabalho é a primeira mediação entre o homem e a realidade material e social. $O$ trabalho também se constitui como prática econômica, obviamente porque nós garantimos nossa existência produzindo riquezas e satisfazendo necessidades [...]. (RAMOS, 2008, p. 4)

As considerações de Ramos nos leva a perceber que o que se pretende com o EMI é a formação integral do ser humano, que possui técnica sim, posto que se vive numa sociedade capitalista e necessita de uma boa base para se inserir no mundo do trabalho de modo mais digno. Mas é também formar para a cidadania crítica, para que este trabalhador seja efetivamente capaz 
de ler o mundo, se posicionar frente ao mesmo, entender seu lugar social e as relações de poder que envolvem sua profissão.

Para que isso ocorra, sem a perda nem dos saberes científicos, nem dos saberes práticos, é preciso que se tenha um currículo que integre não só os conhecimentos disciplinares, mas também extinga a fragmentação saber teórico versus prática. Isso somente é possível quando se concebe o trabalho não apenas pelo viés mercadológico, mas em seus sentidos ontológico e histórico.

Há, porém, algumas dicotomias no currículo integrado: humanidades/ciência e tecnologia; conteúdos/competências. O desafio é desenvolver um ensino humanístico articulado com a formação técnica, de forma a contribuir para uma inovação nos processos de ensinoaprendizagem.

\begin{abstract}
Necessariamente, a construção do currículo integrado exige uma mudança de postura pedagógica; do modo de agir não só dos professores como também dos alunos. Significa uma ruptura com o modelo cultural que hierarquiza os conhecimentos e confere menor valor e até conotação negativa àqueles de ordem técnica, associados de forma preconceituosa ao trabalho manual. É preciso uma disposição verdadeira para o rompimento com a fragmentação dos conteúdos, tendo em vista a busca de inter-relações, de uma coerência de conjunto e a implementação de uma concepção metodológica global. Entender que nesse caso, mais até que em outros, o ensino-aprendizagem é um processo complexo e global. (MACHADO, 2009, p. 82)
\end{abstract}

O currículo integrado parte da perspectiva da totalidade, conhecendo as partes e as relações entre elas. Esta é uma das bases socioculturais presente no PPP do CEFET/RN, a interdisciplinaridade. Que no caso da História ganha ênfase a partir da terceira fase da Escola dos Annales, momento em que há a abertura para o diálogo interdisciplinar.

O currículo do EMI é organizado na perspectiva da integração disciplinar e da relação com o mundo do trabalho primando pela historicidade dos conceitos, considerando sempre os estudantes como sujeitos de seu processo formativo. Isso implica em colocar cada conteúdo em sintonia com o tempo presente. Logo, relacionar teoria-prática, integrar as disciplinas e contribuir para o desenvolvimento das capacidades de observação, experimentação e raciocínio.

Nosso desafio nesse artigo é realizar a interface entre o currículo integrado no âmbito do EMI, especificamente do Curso de Turismo, e o ensino de história. Para tanto, é preciso compreender as transformações empreendidas na pesquisa e no ensino da história na segunda metade do século XX.

A década de 1960, no Brasil, é marcada pela deflagração do Golpe Civil-Militar que se propagou em um regime ditatorial por 21 anos no país. Dentre outras consequências, ocorreu um processo de despolitização das ciências sociais, em detrimento do projeto político ideológico dos governos militares para ampliação de seus poderes.

Na década subsequente, o ensino de História se descaracterizou por unir-se aos estudos sociais e a educação moral e cívica. Como sinaliza Selma Fonseca (2003, p. 21), "Com o golpe militar de 1964, o Estado passa a se preocupar com a necessidade de revigorar o ensino de educação cívica pela ótica da doutrina de segurança nacional, havendo, como contrapartida, a descaracterização e o esvaziamento do ensino de história nas escolas". 
Por que havia a necessidade de modificar o currículo escolar, sobretudo nas áreas humanas? A resposta é clara, havia a necessidade de controlar e reprimir as opiniões e pensamentos dos cidadãos, de forma a eliminar qualquer tipo de resistência ao governo. $E$ as ciências sociais são as que desenvolvem diretamente o pensamento crítico social, e, particularmente, a história é capaz de intervir na realidade social à medida que trabalha diretamente com a memória coletiva.

Após esse período, prevalece o legado do Regime, o olhar superior das demais disciplinas sobre as humanas, problemática que está presente no currículo escolar de modo geral e em especial na EP onde a dualidade humanidades/ciência e tecnologia imprimem uma noção de formação parcial do sujeito, valorizando o saber fazer em função da formação humana integral.

Quanto ao professor, é evidente que os princípios de sua autonomia entrariam em choque com o projeto de segurança nacional. A premissa estabelecida foi de racionalização capitalista que pretendia promover o controle técnico-burocrático sobre os professores, resultando em um processo de proletarização docente. Consequentemente, afastou-se dessa profissão o papel da pesquisa e reflexão sobre a prática, implicando muitas vezes em práticas docentes "mecanizadas", tal qual o conformismo teorizado por Gramsci.

Neste mesmo cenário político, tornou-se compulsória a profissionalização técnica no então denominado secundário. Ainda com acentuada dualidade, já que as ciências, letras e artes eram reduzidas para atender às necessidades do mundo do trabalho. Sob o Regime Militar efetuou-se uma profunda reforma na educação básica por meio da Lei n. 5.692/71 - Lei da Reforma de Ensino de 10 e $2 \circ$ graus - sinalizando para um ensino secundário profissionalizante para todos.

[...] esse governo tinha seu projeto de desenvolvimento do Brasil centrado em uma nova fase de industrialização subalterna, o que ficou conhecido como o milagre brasileiro. Esse milagre demandava por mão-de-obra qualificada (técnicos de nível médio) para atender a tal crescimento. (BRASíLIA, 2007, p. 14)

No contexto da Educação Profissional, em pleno processo de descaracterização das ciências sociais, a história não ocupava um espaço favorável. Nem tampouco, na pesquisa, aspecto que perdurou até meados do século XX. Ao mesmo tempo em que o país ia se redemocratizando, os currículos escolares da maioria dos estados brasileiros iam se reformulando, assim, as propostas curriculares mais atuais para o ensino de História são fruto dos debates e lutas políticas pós Ditadura Militar.

Sobre esse aspecto, assim afirma Fonseca (2003, p. 26):

A partir dos anos [19]90, no contexto neoliberal - conservador, de globalização econômica, as disputas e lutas em torno de uma nova política educacional e da nova Lei de Diretrizes e Bases foram paulatinamente alterando a configuração das dimensões constitutivas do ensino de história. [...] História passou a ser tratada como disciplina autônoma nas últimas séries do fundamental e ampliou seu espaço em nível médio. O conteúdo da história ensinada assumiu diferentes imagens nos diversos espaços onde se processam os debates, as discussões e as reformulações, visando revalorizá-la como campo de saber autônomo fundamental para a formação do pensamento dos cidadãos. 
Nesse cenário de abertura democrática, novas tendências historiográficas e pedagógicas e redefinição do papel dos professores, a postura dos docentes mudou. Não se aceitava mais os currículos como pacotes. Desta forma, o currículo passa a ser tema de debate e produzido democraticamente: poder educacional, academia e profissionais que mais diretamente lidavam com as práticas pedagógicas, os professores.

O público escolar sofreu nas décadas de 1980 e 1990 processos de transformações, causados pelo fluxo migratório do campo para a cidade e as transformações tecnológicas e midiáticas cada vez mais aceleradas, que promovem a comunicação de informações entremeadas por imagens e sons, bem diferentes da forma de transmissão do conhecimento escolar no chão da escola, marcado pela oralidade. Para a História esse aspecto se torna um desafio ainda maior, posto que as transformações tecnológicas implicam em olhar o passado como algo ultrapassado.

[...] Trata-se de gerações que vivem o presenteísmo de forma intensa, sem perceber liames com o passado e que possuem vagas perspectivas em relação ao futuro pelas necessidades impostas pela sociedade de consumo que transforma tudo, incluindo o saber escolar, em mercadoria. A História oferecida para as novas gerações é a do espetáculo, pelos filmes, propagandas, novelas, desfiles carnavalescos [...]. (BITTENCOURT, 2013, p. 14)

Como tornar o saber histórico significativo em meio a um processo de depreciação do passado? A resposta simplória seria colocar em sintonia o passado com as atuais necessidades da sociedade, para efeito de superação do tecnicismo característico da década de 1970, no qual o currículo era organizado de forma estanque e mecanicista.

Entusiasmados, atualmente, pelas transformações sociais, políticas e científicas que afetaram o campo da história, os professores erroneamente passaram a substituir o pensamento analítico por achismos, a investigação bibliográfica por sites de pesquisa, vídeos passaram a substituir os livros e o passado passou a ser visto como algo desprezível. Tudo isso, partindo do pressuposto de que o que não é veloz é chato (PINSKY, PINSKY, 2010).

Não é nosso objetivo investigar o mau uso das novas linguagens no ensino de história como um todo, mas é inevitável salientar que a inserção dessas novas linguagens não é garantia de uma transformação do ensino, haja vista que os mesmos podem contribuir para o caráter linear, conteudista e puramente propedêutico do Ensino de História.

Portanto, a História é uma disciplina humanizadora que não pode se submeter à mera preparação para o ingresso no ensino superior. Mas, deve, sobretudo, atender as necessidades imediatas da juventude, que tem ingressado cada vez mais cedo no mercado de trabalho.

No contexto do Ensino Médio Integrado (EMI), inserir a dimensão do trabalho como princípio educativo é uma condição essencial. Cada estudante deve perceber-se como sujeito histórico, que atuante no mercado de trabalho, precisa entender os pressupostos históricos, sociais, políticos e econômicos que envolvem sua ação profissional.

Neste caso, a história assume papel importante nessa formação, pois parte do reconhecimento dos esforços que nossos antepassados fizeram para chegarmos ao estágio civilizatório que nos encontramos, sem, contudo, dar primazia somente ao passado: 
O passado deve ser interrogado a partir de questões que nos inquietam no presente (caso contrário, estudá-lo fica sem sentido). Portanto, as aulas de História serão muito melhores se conseguirem estabelecer um duplo compromisso: com o passado e o presente. (PINSKY, PINSKY, 2010, p. 23)

Essa relação passado/presente tem sido alvo de debates e questionamentos que perpassam pelas discussões no âmbito da pesquisa e inquietações dos próprios alunos. É comum nos depararmos com a seguinte pergunta: Por que estudar história? É evidente que isso decorre das próprias transformações sociais, que impõem um mundo do aqui, do agora, da velocidade e um ensino que prioriza o passado, tende a tornar-se desconexo e insignificante para os educandos. Para Ana Maria Monteiro (2007), os professores costumam responder ao referido questionamento acentuando a importância do conhecimento histórico na dinâmica da sociedade. Mas os professores que realmente marcam a vida dos alunos são aqueles que estabelecem de forma significativa a relação passado/presente.

Num mundo onde os meios de comunicação acentuam a presentificação do tempo, no qual o "aqui" e o "agora" parecem ocupar todas as atenções e esforços, e onde o antigo é qualificado como velho, obsoleto, e, portanto, descartável, o estudo da História torna-se uma tarefa difícil e desafiadora, para muitos desnecessária. (MONTEIRO, 2007, p.11)

E dentro do universo da EP, como acentuar a importância de ensino de história para a atuação do técnico em guia de turismo? É necessário contribuir para a compreensão da historicidade da vida social, distanciando-se das visões imediatistas e fatalistas, que naturalizam o social. Isso é possível somente por meio da compreensão crítica do passado, que não ocorre essencialmente pela inserção de novas linguagens e tecnologias, mas pelos novos significados que se dão aos acontecimentos, fazendo relações com o contexto sócio-histórico e do mundo do trabalho dos educandos.

As mudanças ocorridas na política educacional na década de 1980 e a consolidação da pedagogia histórico-crítica impuseram uma necessidade de mudança de concepção em todas as áreas do conhecimento, haja vista as novas visões de homem, sociedade e ciência que implicaram em transformações das relações sociais e de produção.

Há, neste cenário, por sua vez, abertura para os estudos curriculares que priorizam a relação educação e trabalho no universo do ensino da história, o que sinaliza para a superação do saber enciclopédico e fragmentado.

A importância de tomarmos o trabalho como princípio de investigação do ensino de história, parte do pressuposto epistemológico marxista de que o trabalho humano, historicamente impulsiona o processo de formação, desenvolvimento e transformação do modo de produção da existência humana, e, por conseguinte, é atividade criadora. Assim, o homem, pelo trabalho, vai se transformando e transformando a natureza, dominando-a, descobrindo suas leis; vai acumulando experiências/vivências que se transformam em teorias, ciência e saber. (HORN, GERMANI, 2009, p. 10)

Deste modo, é emergente que o ensino de história tome o trabalho e suas relações produtivas como elemento fundamental da história da humanidade, em especial no âmbito da educação profissional. Inserir o trabalho como categoria do ensino, implica em uma nova 
estruturação do currículo e uma seleção dos conteúdos, superando o processo histórico-cultural que reflete a hegemonia de determinados saberes sobre outros.

Historicamente a organização do conhecimento ocorre sob o julgo das relações de poder socialmente produzidas, o que culmina na estratificação do conhecimento e um currículo utilitarista. Por isso, não é possível se compreender o currículo sem inseri-lo no amplo quadro econômico, cultural e político vigente. No entanto, o que vinha delimitando a estrutura curricular da história eram os modos de produção, resumindo seu ensino a uma única dimensão social.

Os modos de produção ordenam as etapas e conteúdos da maior parte das propostas para as 5 a séries em diante, embora o Brasil continue sendo analisado por intermédio dos três grandes eixos políticos, Colônia, Império, República, buscando articulá-los aos ciclos econômicos - do pau-brasil à industrialização. As mudanças mais significativas surgem com propostas que ordenam 0 conhecimento histórico por temas, sejam os originários de temas geradores, segundo os pressupostos freirianos, ou pelos eixos temáticos. (BITTENCOURT, 2013, p. 15-16)

Nesse sentido, abre-se espaço para outros aspectos além do econômico. Para Bittencourt, a justificativa para o trabalho com eixos temáticos é a impossibilidade de se estudar toda a história da humanidade e superar a noção de tempo evolutivo e linear. Inserem-se nesse contexto as percepções de semelhanças e diferenças, rupturas e continuidades, dando ao docente a possibilidade de trabalhar os conceitos históricos mais aproximados das necessidades imediatas dos alunos, aproximando passado/presente.

A partir dessa percepção, entendemos que o objeto da história e sua historicidade sofrem modificações ao longo do tempo. Tomando por base, por exemplo, o início da modernidade (sob influência do Renascimento e Reforma Protestante) percebemos que somente eram considerados autênticos e viáveis à pesquisa histórica os fatos e textos que fossem meticulosamente averiguados (HORN, GERMANI, 2009). A noção de verdade era fortemente arraigada à tarefa do historiador, o que implicava em ter o discurso histórico como objeto pronto e acabado, portanto, inquestionável.

Com o advento do lluminismo, abre-se espaço para uma nova concepção de homem, de ciência e particularmente de História, a qual ganhou novos procedimentos de análise.

Mas, segundo Furet, somente em fins do século XIX (na Europa), ao lado dos movimentos de laicização da sociedade e da formação dos Estados Nacionais modernos, é que a História surge, realmente, como disciplina escolar autônoma. A História nasce enquanto disciplina nas propostas curriculares, tendo como grande temática o Estado-nação. Ou seja, a nação passa a ser o objeto assumido pela História. [...] No Brasil, a História como disciplina curricular se constituiu, segundo Nadai (1992), de forma idêntica à da Europa (como analisou Furet), o que ocorreu a partir do discurso laicizado em defesa da História Universal, opondo-se ao poder da Igreja [...]. Diante dessa constatação, é possível afirmar que o ensino de História desde fins do século XIX, quando da sua inclusão nos programas e guias curriculares, sofreu influência das tradições europeias, herdando o esquema quadripartido francês: Idade Antiga, Idade Média, Idade Moderna e Idade Contemporânea. Tal situação em nada surpreende, ao contrário, está em plena consonância com o movimento republicano e os ideais positivistas em expansão 
e praticamente hegemônicos no Brasil no final do século XIX. (HORN, GERMANI, 2009, p. 27. Grifo nosso)

Embora tenha ocorrido a renovação dessa perspectiva, a partir de meados do século XX, ainda é predominante nos currículos escolares essa concepção de História Universal e a lógica quadripartida. Após as Reformas Francisco Campos (1931) e a Reforma Capanema (1942), o esquema Francês é subdividido em História Universal e História do Brasil, ainda prevalecendo a visão eurocêntrica, a sequencialidade e linearidade do conhecimento histórico.

A partir dos anos 1980, no contexto da reabertura política do país, empreende-se um forte debate acerca do que e como ensinar história. Buscou-se, na ocasião, superar a sequencialidade e a supremacia dos conteúdos em detrimento da crítica, análise e interpretação dos fatos, e como solução para tal problemática emerge a História Integrada e o trabalho com Eixos Temáticos. É preciso esclarecer que os conteúdos ainda devem ocupar um lugar central no processo de ensinoaprendizagem, porém é preciso diversificar na apresentação dos mesmos e no significado que estes exercem na vida social e produtiva dos estudantes, em especial no caso do EMI, por isso, sua seleção e escolha devem atender às necessidades da formação humana integral.

Já as propostas curriculares que concebem o currículo e a educação dentro dos padrões mais atualizados constroem a trama expositiva procurando envolver 0 aluno por meio da problematização do tema, de sua abordagem, da relação necessária com o mundo cultural do aluno; as atividades constituem o cerne do trabalho pedagógico apresentado, pensando sempre do ponto de vista da construção de um conhecimento escolar significativo [...]. (BEZERRA, 2010, p. 41)

Neste sentido, em um espaço de formação do técnico em guia de turismo é fundamental que os alunos compreendam o processo de produção de sua existência e as relações de trabalho numa perspectiva histórica, especialmente no que consta às relações de poder, presente na dimensão social, pública e privada. A noção de ensino de história como mecanismo de formação do pensamento crítico não é novidade. O que é nova é a ênfase na compreensão de "sentir-se sujeito histórico" (BITTENCOURT, 2013), que resvala diretamente na dimensão educação/trabalho.

Compreender-se enquanto sujeitos da história exige uma percepção do que é ser cidadão, noção amplamente recorrente nos discursos dos estudiosos da área.

[...] o ensino de História deve contribuir para libertar o individuo do tempo presente e da imobilidade diante dos acontecimentos, para que possa entender que cidadania não se constitui em direitos concedidos pelo poder instituído, mas tem sido obtida em lutas constantes em suas diversas dimensões. (BITTENCOURT, 2013, p. 20)

Comumente, se convencionou estudar a cidadania política, dentro dos padrões democráticos do modelo liberal. Formar para a cidadania numa perspectiva contra hegemônica é entender as suas dimensões sociais: igualdade, justiça, diferenças, lutas e conquistas, compromissos e rupturas. Associando cidadania social e política, e cidadania e trabalho (BITTENCOURT, 2013).

Entender o currículo a partir da relação educação/trabalho implica compreender e rediscutir a perspectiva materialista da história, haja vista que é uma combinação mais recorrente, embora essa combinação possa ocorrer em outras dimensões e vertentes teóricas. 
Nesta corrente de pensamento a cultura não se dissocia da realidade e o trabalho é produtor da cultura, estando diretamente ligado ao processo de hominização. Criticando-se o tempo histórico cronológico, evolutivo, progressista e eurocêntrico, por exemplo, a história do Brasil "inicia-se" sob a ordem de outro espaço nacional, Portugal, lugar do capitalismo emergente. Por isso, se propõe uma nova divisão dos estudos históricos sob a ótica do trabalho.

\begin{abstract}
A importância que levou Marx a tomar o trabalho como categoria de investigação científica da História parte do pressuposto de que o trabalho humano, historicamente, impulsiona o processo de formação, desenvolvimento e transformação do modo de produção da existência humana e, por conseguinte, é atividade pela qual o homem domina as forças naturais: humaniza a natureza e se humaniza, autoproduzindo-se. (HORN, GERMANI, 2009, p. 40-41)
\end{abstract}

Essa é uma percepção que possibilita no espaço da EP, a inserção do trabalho em seus sentidos ontológico, histórico e social, não resumindo-a a prática produtiva. Sem, contudo deixar de entender que as transformações no mundo do trabalho são frutos de um cenário também cultural e político, o que permite fazer inferências e comparações entre diferentes temporalidades. Assim, dando aos discentes as condições necessárias para pensar sobre seu lugar histórico e conscientizar quanto ao modelo de produção no qual está inserido.

\begin{abstract}
Os desafios enfrentados na elaboração das propostas residem substancialmente em articular a produção historiográfica que introduz o social e o cultural em suas relações intrínsecas com o econômico e que redimensionam o político. Na crítica sobre as propostas que elencam acontecimentos da política institucional há, por vezes, o abandono do político, em uma visão fragmentada do social. Alguns conceitos como os de classe social, trabalho e alienação poderiam ser mais bem explicitados para a formulação de lutas e movimentos sociais, estendendo a concepção de ação política para a esfera das organizações da sociedade civil, dos sindicatos e de lutas de resistências diversas, conforme preconizam estudos do cotidiano [...]. (BITTENCOURT, 2013, p. 25)
\end{abstract}

Portanto, é necessário e emergente estudar as diversas facetas do sistema capitalista para compreender o mundo do trabalho e suas problemáticas, comparando as permanências e rupturas com o tempo presente. Estudar o capitalismo, por sua vez, implica compreender o tempo da natureza, que comandou o ritmo da sociedade a partir do neolítico; e o tempo da fábrica, que dominou a vida das pessoas (trabalho e lazer) e da política (guerras e crises).

É notório que o ensino de história precisa englobar o mundo do trabalho como categoria fundamental em diferentes níveis do ensino, e em especial na modalidade EP. O modo como ele vai ser abordado é que deve ser investigado, por isso, avaliamos o PPC do curso de turismo na expectativa de compreender a concepção de história, currículo e trabalho presente neste documento para então associar com o discurso dos docentes acerca dessas mesmas temáticas.

\title{
3 ENSINO DE HISTÓRIA E O PPC NO CONTEXTO DA FORMAÇÃO DO TÉCNICO EM TURISMO NO CEFET/IFRN
}

A estrutura curricular do curso de Turismo na modalidade integrado dava-se pela integração dos núcleos comum, da parte diversificada e da formação profissional. O núcleo comum 
correspondia às disciplinas das áreas do conhecimento do Ensino Médio: Linguagens e Códigos e suas Tecnologias; Ciências Humanas e suas Tecnologias e Ciências da natureza, matemática e suas tecnologias. A parte diversificada englobava as disciplinas voltadas para a compreensão do mundo do trabalho de modo geral; e, o núcleo de formação profissional integrava as disciplinas específicas da área do turismo.

Observamos nessa matriz, que nos dois primeiros anos do curso, o currículo era centrado no núcleo comum, ou seja, disciplinas relacionadas ao ensino médio não profissional. O que acentua, em alguns momentos, a dualidade, inclusive, uma das problemáticas levantadas pelos estudantes, os quais afirmaram que nos primeiros anos não pareciam estar estudando em uma instituição de formação profissional.

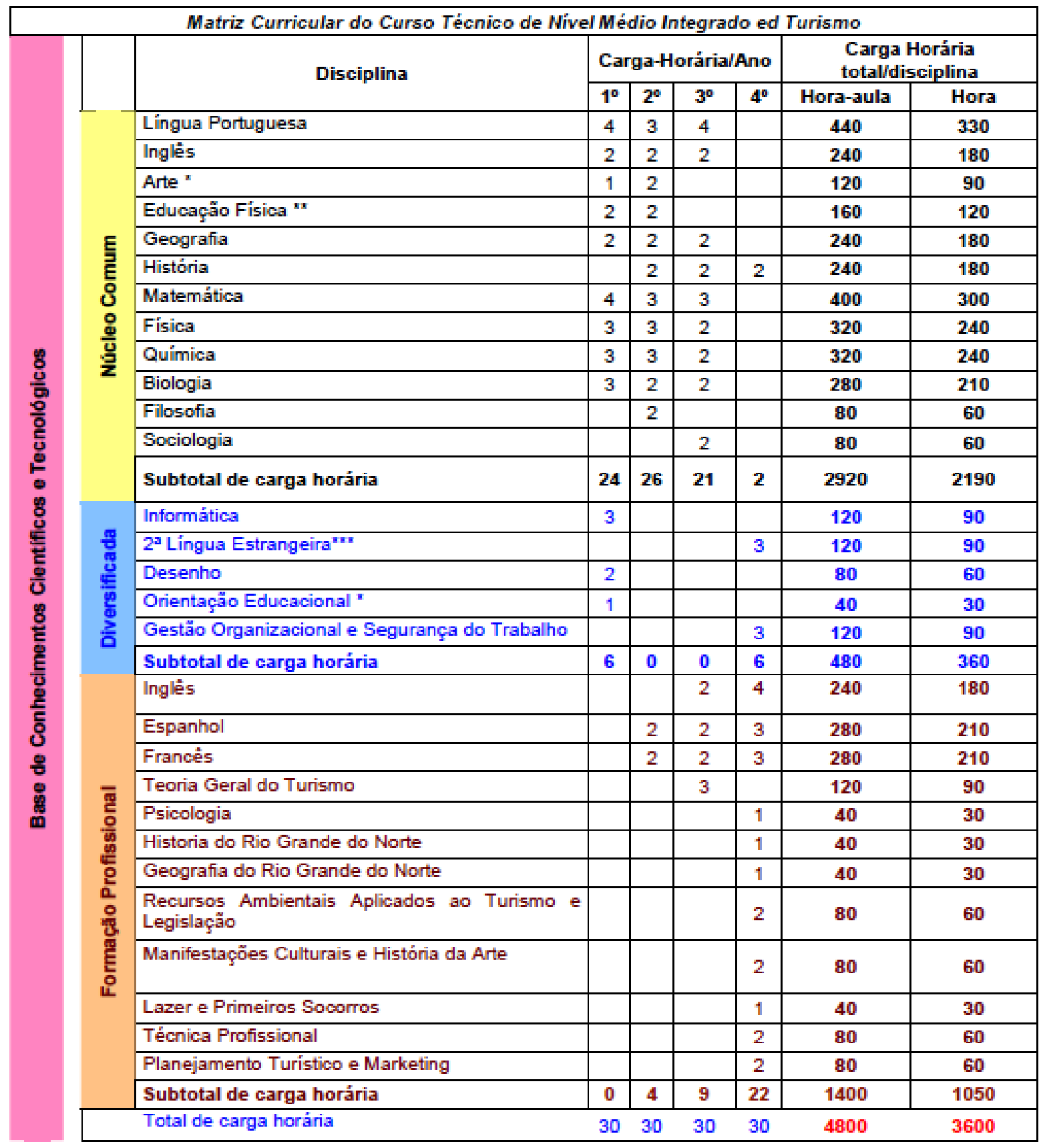

Figura 1: Matriz Curricular do Curso Técnico de Nível Médio Integrado em Turismo 
No caso do ensino de história, na segunda série, havia a então denominada História I; na terceira série, História II; na quarta série, História III, todas com uma carga horária de 80h/aulas, essa organização se refere ao núcleo comum como pode ser observado na Figura 1.

Quanto ao núcleo da formação profissional, existiam as disciplinas de Manifestações Culturais e História da Arte com carga horária de 80h/aula e História do Rio Grande do Norte com 40h/aula, ambas na quarta série (ver Figura 1).

Observamos que no núcleo comum a organização dos conteúdos era linear, eurocêntrica e seguia a lógica da divisão francesa da História, indo desde a pré-história até as revoluções liberais do século XIX ${ }^{1}$. Analisando os objetivos para estas três unidades de trabalho, podemos concluir que não havia muita ênfase na relação entre o passado e o mundo presente, nem tampouco do conhecimento histórico com mundo do trabalho, como é sugerido nas bases epistemológicas tanto do PPP do CEFET/RN quanto do Plano de Curso de Turismo, este último aponta como justificativa, dentre outras coisas:

Estão presentes também, como marco orientador desta proposta, as decisões institucionais traduzidas nos objetivos desta instituição e na compreensão da educação como uma prática social, os quais se materializam na função social do CEFET/RN de promover educação científico-tecnológico-humanística visando à formação integral do profissional-cidadão crítico-reflexivo, competente técnica e eticamente e comprometido efetivamente com as transformações sociais, políticas e culturais e em condições de atuar no mundo do trabalho na perspectiva da edificação de uma sociedade mais justa e igualitária, através da formação inicial e continuada de trabalhadores; da educação profissional técnica de nível médio; da educação profissional tecnológica de graduação e pósgraduação; e da formação de professores fundamentadas na construção, reconstrução e transmissão do conhecimento. (PPC-Turismo, 2005. Grifo nosso)

Fica explícita, nesse trecho, a preocupação em formar integralmente os sujeitos visando, sobretudo, a inserção na atividade laboral. Por outro lado, essa perspectiva esbarra na organização das ementas das disciplinas que, como já mencionado, expõe objetivos que não assumem essa lógica, pelo contrário, atendem basicamente a demanda dos conteúdos pelos próprios conteúdos. Embora desde História I já se estabeleça relações entre os conteúdos e a ascensão e desenvolvimento do capitalismo, que abre margem para que na prática do professor se insira as relações históricas entre o modo de produção e a exploração do trabalhador.

Nas bases científico-tecnológicas, os conteúdos de História I se organizavam cronologicamente e pouco se aproximavam da História do Brasil, com exceção da pré-história. No geral, prevalecia a visão eurocêntrica e sequencialista. Lembremos, pois, das nossas discussões anteriores, falávamos de uma nova perspectiva curricular para o ensino de História, a partir do Marxismo e do movimento dos Annales, assim como de um currículo integrado para o Ensino Médio, ambos sinalizando transformações curriculares e práticas renovadoras.

No entanto, o PPC de turismo, no âmbito da História, ainda seguia a lógica vigente no século XIX, fator que nos incita a pensar em como o mundo do trabalho poderia ser inserido neste

\footnotetext{
${ }^{1}$ Essas informações são encontradas no PPC do Curso de Turismo, na parte das ementas de cada disciplina. BRASIL. Curso Técnico de Nível Médio Integrado - Turismo: Plano de Curso. Autorizado pela Resolução № 05/2005-CD-CEFETRN. Disponível no arquivo eletrônico institucional do IFRN - Campus Cidade Alta, 2005.
} 
contexto, se no próprio currículo essa dimensão não aparecia de maneira clara? Isso nos leva a crer que o caráter propedêutico se sobrepujava à formação profissional no âmbito do currículo formal, sobretudo no núcleo comum.

Somente em História II é que aparecera como eixo temático o tema Trabalho e cidadania. Há um expressivo avanço no que diz respeito à organização cronológica do conhecimento, inserindo uma perspectiva idealizada por Eric Hobsbawm (1977) no livro A Era das Revoluções, que redefine a cronologia dos acontecimentos a partir do século XVIII sob a perspectiva das grandes revoluções que ocorreram no cenário europeu.

$\mathrm{Na}$ ementa da disciplina aparecem três grandes temáticas: transição do feudalismo ao capitalismo, a Era das Revoluções I, a Era das Revoluções II e sociedade agrária e exclusão no Brasil do século XIX; em todos esses eixos aparecem o tópico trabalho e cidadania. Chama atenção o último tópico onde se discute o trabalho escravo no Brasil, e coloca-se a cidadania como algo negado nesse período.

Pertinente perceber que a concepção de cidadania está atrelada ao conceito de trabalho livre e como algo concedido verticalmente pelo poder instituído. Seria a dualidade entre a cidadania política e a cidadania social e que, sendo abordada apenas em uma dimensão, coloca os sujeitos no espaço de subsunção aos mecanismos de exploração e desigualdades. Haja vista que o fato de ser trabalhador assalariado não exime a possibilidade de negação da cidadania como acontecia de maneira mais evidente com os escravos. Embora a ementa de História II apresente esses paradoxos, é um avanço no que diz respeito à relação entre o ensino de história e o mundo do trabalho e a cidadania.

\begin{tabular}{|c|c|}
\hline & $\begin{array}{r}\text { Curso Técnico de Nivel Médio em Turismo } \\
\text { @ CEFET-RN } 2004\end{array}$ \\
\hline Curso: Técnico de Nivel Médio em Turism & \\
\hline Área Profissional: Turismo e Hospitalidade & Período Letivo: $3^{\text {a }}$ Série \\
\hline Disciplina: História II & Carga-Horária: 60 h $(80$ h/a $)$ \\
\hline \multicolumn{2}{|c|}{ Objetivos } \\
\hline \multicolumn{2}{|c|}{$\begin{array}{l}\text { - Compreender o processo de transição da sociedade feudal para a sociedade capitalista; } \\
\text { - Identificar os elementos constituintes da modernidade e o processo de consolidação do Estado burguês, através do } \\
\text { estudo das Revoluçőes burguesas - Revolução Industrial e Revolução Francesa; } \\
\text { - Compreender como o Brasil se insere no contexto de tais transformações bem como se dá o processo de formação da } \\
\text { sociedade brasileira a partir da colonização. }\end{array}$} \\
\hline \multicolumn{2}{|c|}{ Bases Científico-Tecnológicas (Conteúdos) } \\
\hline $\begin{array}{l}\text { 1. As transformações nas relações sociais na transição } \\
\text { do Feudalismo para o Capitalismo } \\
\text { 1.1. O trabalho e cidadania } \\
\text { 1.2. O Antigo Regime: mercantilismo, absolutismo e } \\
\text { colonialismo } \\
\text { 1.3. Sociedade agrária e exclusão no Brasil colonial } \\
\text { 2. A Era das Revoluções I } \\
\text { 2.1. A Revolução Industrial } \\
\text { 2.2. Trabalho e cidadania }\end{array}$ & $\begin{array}{l}\text { 3. A Era das Revoluções II } \\
\text { 3.1. A era das luzes } \\
\text { 3.2. As duas revoluções políticas: americana e francesa } \\
\text { 3.3. Trabalho e cidadania } \\
\text { 3.4. Ecos das revoluções liberais no mundo colonial - a } \\
\text { independência da América portuguesa e da América } \\
\text { espanhola } \\
\text { 4. Sociedade agrária e exclusão no Brasil do Século XIX } \\
\text { 4.1. O trabalho escravo e cidadania negada }\end{array}$ \\
\hline
\end{tabular}

Figura 2: Fragmento da Ementa de História II

Segundo Horn e Germani (2009), o trabalho como fundamento para o ensino de História exige uma nova organização de seu conhecimento, que vise atender aos aspectos sócio-políticoculturais, ou seja, ao modo de produção vigente em cada momento histórico. 
Através do movimento da história, Marx distinguiu uma sucessão de modos de produção, ou seja, antigo, feudal e capitalista. Bourdé e Martin, ao discutirem essa questão, explicaram que a periodização enquanto tal não é nova. [...] A perspectiva de Marx, no entanto, se diferencia das classificações precedentes no sentido gnosiológico da abordagem, na medida em que define o modo de produção a partir da base material e das relações de produção próprias de cada período histórico. Assim, o modo de produção antigo se caracteriza pelo trabalho escravo presente no mundo helenístico e romano; o modo de produção feudal constitui-se pela produção servil do Ocidente Medieval; modo de produção capitalista corresponde ao desenvolvimento das relações de produção assalariada, que surge na Europa a partir das revoluções burguesas e que se manifesta nos dias de hoje, de forma hegemônica. (HORN, GERMANI, 2009, p. 39)

A organização do conhecimento histórico em História II era muito próxima da proposta marxista discutida por Horn e Germani. Essa perspectiva esteve presente também no módulo subsequente, História III. É importante salientar que somente nesse momento é que a história do Brasil é posta em destaque, abrangendo os séculos XIX e XX. Essa é uma fragilidade do referido PPC, visto que concentra o estudo histórico no modelo eurocêntrico, distanciando-se das vivências sociais dos estudantes.

É preciso inserir situações problemas do contexto nacional e local no currículo como forma de vencer o desafio de formar cidadãos críticos, política e socialmente. Porém, a excessiva concentração dos estudos históricos a partir dos acontecimentos europeus, que deveriam aparecer como suporte para entender a história nacional e local, dando a estes últimos, situação de destaque, acaba por relegá-los um caráter diminuto. Na lógica do PPC em análise, somente no terceiro e último ano é que a história do Brasil e RN são trabalhadas, sem levar em consideração, por exemplo, a constituição sociocultural antes do processo de colonização.

Analisando a disciplina História do Rio Grande do Norte, identificamos que assim como as demais (História I, II e III) não havia a mínima aproximação com a história integrada ou os eixos temáticos, pelo contrário, havia uma listagem de conteúdos pragmática, linear, e, em grande medida, conservadora. Vejamos o trecho do PPC que especifica os conteúdos contemplados nessa disciplina:

Bases Científico-Tecnológicas (Conteúdos): Aspectos históricos do Rio Grande do Norte, Formação do povoamento e da sociedade, Conquista e a colonização, Origem dos municípios, Ciclos econômicos, Fatos Históricos relevantes, Sítios Históricos ou monumentos isolados, Museus com acervos históricos, Globalização. (PPC - Turismo, 2005, p. 69)

Entendemos que o discurso formal indicia uma resistência em inserir as transformações empreendidas na historiografia e consequentemente no Ensino de História durante o século XX. Evidentemente que a ausência de diálogo com a renovação historiográfica implica em manutenção da visão da história ensinada aos moldes do século XIX, dificultando o trabalho com situações problemas como sinaliza Janice Theodoro (2010, p. 51):

Como somos historiadores, podemos abrir caminho observando que só há um fato histórico no interior de uma situação-problema. Se não há questão não nos resta nada ou quase nada a fazer. Portanto, para que possamos vencer o desafio da vida contemporânea temos que problematizar a realidade que nos cerca. Para problematizar, o primeiro passo é conhecer. 
Concordamos com Theodoro que é sim necessário o saber relacionado ao conteúdo, mas este deve partir de inquietações do presente, problemáticas incitadas pelos próprios alunos e professores, de modo que se dê significado aos conteúdos, torne-os significativos e prazerosos. Em detrimento dessa necessidade, o espaço da história no PPC de Turismo (2005) aponta grandes resquícios do positivismo.

\section{O CURRÍCULO PRATICADO: RESULTADOS E DISCUSSÕES}

Para compreender como o currículo praticado lidava com essas questões, entrevistamos professores que atuaram no curso técnico integrado de turismo. Nesses diálogos pudemos identificar processos de prática imitativa e prática criativa frente ao currículo formal.

A primeira grande problemática identificada no relato dos sujeitos se relacionou à formação do licenciado, não houve em nenhum dos casos uma preparação acadêmica para atuar na modalidade educação profissional. Elucidamos, então, a fala do professor Darcy ${ }^{2}$, o qual aponta o espaço de atuação docente como momento de compreensão do que venha a ser a EP, embora entendamos que essa apreensão se dá a despeito de construções conceituais extremamente importantes para o profissional da área, tais como: relação educação/trabalho, dicotomia trabalho manual/trabalho mecânico, políticas públicas para o EMI, entre outras.

[...] a princípio quando eu entrei aqui, na minha cabeça ainda não tinha aquela conexão direta da minha área de atuação de História, da disciplina de História, com o enfoque técnico profissional, formação para um mercado de trabalho. Eu vim aprendendo isso ao longo do caminho, com os professores que já estavam aqui e em como a gente poderia construir um ensino de história voltado para os interesses dos cursos técnicos? Como a história poderia se voltar para uma coisa mais específica dos cursos desenvolvidos pela instituição? Então foi aí que eu comecei a perceber essa conexão da história com o mundo do trabalho [...]. (PROFESSOR DARCY. Depoimento [Agosto de 2014]. Entrevistadora Aline Cristina da Silva Lima. Natal, 2014. Gravador formato MP3. Entrevista concedida à pesquisa sobre práticas pedagógicas dos professores de História que atuaram entre os anos de 2005-2011 no Curso Técnico de Nível Médio Integrado de Turismo. Grifo nosso)

A concepção desse professor era de que o CEFET/RN formava para o mercado de trabalho, entendendo o trabalho enquanto atividade produtiva, mercadológica. Não aparece na fala desse sujeito o conceito multidimensional do trabalho, em outros termos, o ensino de História era responsável pela formação geral, e as disciplinas do núcleo profissional formaria o técnico, o que denota uma separação entre o homo faber e o homo sapiens. Segundo Darcy, foi na vivência profissional que ele começou a perceber os liames entre ensino de História e mundo do trabalho, numa perspectiva de formação omnilateral, que o mesmo categoriza como formação do técnico cidadão.

O termo cidadania aparece associado ao Ensino de História, por meio de práticas analíticas da sociedade e do papel social dos estudantes. Formar o cidadão é, pois, conscientizar acerca da

\footnotetext{
${ }^{2}$ Licenciado e Bacharel em História, com especialização em Educação. Ingressou na Rede Federal de Ensino do Rio Grande do Norte no ano de 1991.
} 
participação política e do mundo produtivo. Tal qual aparece nas ementas da disciplina, ser cidadão é ser também um trabalhador livre.

[...] Então, faz parte da compreensão também do aluno que a política é um jogo independente da vida dele. Então quando você consegue trabalhar na perspectiva que eles se enxerguem como cidadão participando também, que vai estar inserido no mercado de trabalho, que vai ser um cidadão produtivo, eles começam a dialogar melhor. Uma das grandes tentativas da gente, ao longo de todos esses anos na escola, é realmente fazer com que o aluno se apaixone pela disciplina. Ele se veja útil, faça conexões a sua vida com os temas que são trabalhados na escola. (PROFESSOR DARCY. Depoimento [Agosto de 2014]. Entrevistadora Aline Cristina da Silva Lima. Natal, 2014. Gravador formato MP3. Entrevista concedida à pesquisa sobre práticas pedagógicas dos professores de História que atuaram entre os anos de 2005-2011 no Curso Técnico de Nível Médio Integrado de Turismo)

Mesmo sutilmente há a noção de cidadania política e social, embora o social apareça representado apenas pelo trabalho. Pouco se esboçou acerca da igualdade, justiça, diferenças, e lutas sociais.

Ainda sobre a formação docente, os demais professores também afirmaram não ter nos currículos de suas licenciaturas abertura para a relação Ensino de História/trabalho. Algo que nos chama a atenção é que ao serem questionados acerca dessa relação, Maria e Anísio afirmaram que houve em suas formações uma noção da atuação docente, mas não a analogia entre conteúdos curriculares de História e trabalho como práxis humana. Assim, todos construíram suas concepções de formação humana integral na vivência.

Entendemos, assim, que os saberes do conhecimento disciplinar não são suficientes para o saber fazer do professor, que existem outras dimensões da formação profissional que António Nóvoa (1997) denomina de saberes experienciais e saberes pedagógicos. Por isso, não se pode analisar a prática docente sem compreender a trajetória acadêmico-profissional do sujeito, tendo em vista que: "[...] há o reconhecimento de que não é possível construir um conhecimento pedagógico para além dos professores, isto é, que ignore as dimensões pessoais e profissionais do trabalho docente." (NÓVOA, 1997, p. 32)

Durante muito tempo vigorou a ideia de que o saber disciplinar era suficiente para a atuação do docente, "Depois dos anos 60, a expansão da escola e a profissionalização do ensino provocaram uma espécie de primado da pedagogia. [...]," (NÒVOA, 1997, p. 35), pretendia-se insinuar que no fundo, o essencial era o domínio das técnicas e dos processos pedagógicos, no entanto, reafirmamos que é necessário conhecer a fundo sua disciplina, e no caso da história, Pinsky e Pinsky (2010, p. 19) assim afirmam:

É preciso, nesse momento, mostrar que é possível desenvolver uma prática de ensino de História adequada aos novos tempos (e alunos): rica de conteúdo, socialmente responsável e sem ingenuidade ou nostalgia. Historiador/professor sem utopia é cronista e, sem conteúdo, nem cronista pode ser.

Não existia uma sistemática de trabalho institucional voltada para a formação continuada que suprisse as carências desses docentes no que tange a atuação na EP, por isso, quando 
questionado sobre o contato com a modalidade EP na sua formação, assim nos afirmou o professor Anísio3:

[...] Lógico que tinha a ideia do trabalho docente, da atuação em sala de aula, mais não especificamente para lecionar para um curso que fosse direcionado para formação profissional, por exemplo, a ênfase da nossa instituição do atual IFRN. [...]. Quando fui aprovado essa era uma grande preocupação minha de fato, a história ser uma disciplina eminentemente da área das humanidades e como o alunado era uma grande preocupação, como o corpo discente da escola via as disciplinas mais de formação geral, uma vez que a ênfase da escola era no ensino para a formação profissionalizante. Isso foi uma grande preocupação inicial minha, inclusive, no âmbito dos colegas de profissão também, mais previamente em casa. Como sempre tive uma concepção de que história é fundamental para a formação do ser humano. Eu provoco muito meus alunos em sala de aula com sentido de despertar essa compreensão neles, não de ser arrogante, prepotente, de maneira nenhuma nesse sentido, mas de sentido que eles compreendam que estudar história é fundamental para a formação de qualquer profissional em qualquer área que seja [...]. (PROFESSOR ANÍSIO. Depoimento [Agosto de 2014]. Entrevistadora Aline Cristina da Silva Lima. Natal, 2014. Gravador formato MP3. Entrevista concedida à pesquisa sobre práticas pedagógicas dos professores de História que atuaram entre os anos de 2005-2011 no Curso Técnico de Nível Médio Integrado de Turismo)

Mediante a deficiência de formação para atuação na EP, os docentes buscaram integrar o conhecimento histórico ao mundo do trabalho, mesmo que de maneira pontual, como no caso do projeto desenvolvido pela professora $\mathrm{Maria}^{4}$, intitulado "Meu curso e a história: a interdisciplinaridade no curso técnico integrado do Instituto Federal de Educação, Ciência e Tecnologia do Rio Grande do Norte", desenvolvido no ano de 2010.

O trabalho se propôs a um diálogo entre a formação técnica profissional dos educandos e os conteúdos históricos da 3 a série. O objetivo do projeto era despertar a pesquisa, possibilitar novas abordagens históricas e maior compreensão dos conteúdos. $O$ trabalho foi realizado com várias turmas de cursos técnicos integrados, mas no caso do curso de turismo, teve como conteúdos bases: a Revolução Industrial, o lluminismo e A Economia e a Sociedade Colonial, em todos esses os alunos deveriam construir relações entre o turismo e o contexto histórico. A professora Maria esclarece na entrevista como se desenrolou o trabalho:

[...]. Mas o que aconteceu no ano de 2010, foi que eu resolvi aproximar mais esses assuntos da realidade. Nesse ano eu percebi que poderia ter um diferencial [...]. Eu fiz o projeto, mas isso só foi aplicado em um bimestre, porque dá muito trabalho pra gente e pros alunos, esse projeto "Meu curso e a história", com os temas do bimestre. Os alunos escolheriam daqueles temas a relação daquele tema com o curso deles. Então, por exemplo, em diferentes assuntos, como a escravidão no Brasil [...], Iluminismo, Revolução Industrial, tudo isso. Que eram temas que faziam parte do terceiro bimestre, como esses assuntos seriam relacionados com aqueles cursos? Então foi muito interessante, o curso de

\footnotetext{
${ }^{3}$ Licenciado e Bacharel em História, mestre em Ciências Sociais e doutorando em Educação. Ingressou na Rede Federal de Ensino do Rio Grande do Norte no ano de 2006.

${ }^{4}$ Formada em História, mestre em Administração e Doutora em Educação. Ingressou na Rede Federal de Ensino do Rio Grande do Norte no ano de 1996.
} 
turismo, eu me lembro, a questão da sociedade mineradora foi assim um dos assuntos escolhidos que foi muito discutido pelo grupo, porque eles começaram a ver a questão do deslocamento da terra [...]. Outros grupos pesquisaram sobre o desenvolvimento da burguesia, sobre a viagem turística, o turismo "grande tour" que era feito na Europa, pela sociedade burguesa [...]. (PROFESSORA MARIA. Depoimento [Agosto de 2014]. Entrevistadora Aline Cristina da Silva Lima. Natal, 2014. Gravador formato MP3. Entrevista concedida à pesquisa sobre práticas pedagógicas dos professores de História que atuaram entre os anos de 2005-2011 no Curso Técnico de Nível Médio Integrado de Turismo)

Para efeito de análise de sua própria ação, a docente Maria submeteu um artigo na Revista Holos (2010), nesse texto aparecem as relações que os alunos conseguiram construir nos trabalhos. Os grupos da Revolução Industrial, por exemplo, esclareceram que devido à nova divisão do tempo, a emergência da concepção de tempo inoperante, as lutas e conquistas sociais dos direitos dos trabalhadores e as novas necessidades da vida urbana deram suporte ao surgimento da atividade turística e, logicamente, ao trabalho do guia. No caso dos estudantes que pesquisaram a Sociedade e Economia Colonial, assim afirma Oliveira e Silva (2013, p. 251),

O trabalho que relacionou o turismo com A Economia e a Sociedade Colonial explorou o turismo nas cidades coloniais como Ouro Preto, Tiradentes e outras cidades de heranças coloniais que atualmente tem na atividade turística uma grande fonte de renda. A pesquisa destaca os monumentos históricos como as igrejas de Minas Gerais, em Ouro Preto, cujo interior é adornado por ouro e ressalta as obras barrocas de autoria de Antônio Francisco Lisboa, popularmente conhecido como Aleijadinho.

Observam-se quão os estudantes amadureceram suas percepções acerca do conhecimento acumulado historicamente e o mundo do trabalho, especificamente no que concerne aos trabalhadores da área do turismo. Tanto no aspecto de surgimento dessa atividade, como na relação entre a história nacional e local, com seus patrimônios e peculiaridades, e as atividades turísticas então vigentes.

O trabalho desenvolvido pela professora Maria nos remete à discussão realizada anteriormente no que diz respeito a dar novos significados ao conhecimento histórico, significados que estejam relacionados com a vivência dos alunos e, no caso da EP, com o curso de formação em que eles estavam inseridos, a dimensão "trabalho" ganhou nesse projeto um viés de compreensão histórica do surgimento da atividade turística, logo, da atuação dos profissionais dessa área.

Um aspecto importante dessa ação docente é a superação da memorização mecânica comum em algumas práticas dos professores de história e a inserção dos alunos enquanto protagonistas de sua aprendizagem. Assim,

Através da pesquisa os alunos puderam sentir, além da ruptura dos limites impostos pelas disciplinas, o prazer e a dinâmica que acompanham os agentes históricos ativos no processo de construção do conhecimento, a partir do momento que eles souberem conduzir uma pesquisa, elegeram um objeto e trabalharam com esse objeto chegando finalmente a uma conclusão. (OLIVEIRA; SILVA, 2013, p. 254. Grifo nosso) 
Para fundamentar a análise de sua prática, a autora do referido artigo, buscou historicizar a presença da disciplina História no currículo da Rede Federal de Ensino de Natal, perpassando pela ETFRN, CEFET/RN e IFRN, apontando questões como a influência da conjuntura da Ditadura Militar no Brasil e a grande concentração do pensamento positivista e de fragmentação do conhecimento, que colabora com a alienação e a mecanização nos processos de formação e atuação profissional. Segundo Maria, somente na década de 1990, é que se renovam as maneiras de se pensar o Ensino de História e seu currículo, abrindo espaço para o trabalho com diferentes temporalidades, sobretudo com os eixos temáticos.

Nessa linha de pensamento, ela considera a interdisciplinaridade como fundamento para a transformação das práticas pedagógicas. Como a:

[...] flexibilização dos conteúdos a serem desenvolvidos, possibilitando mudanças no currículo das escolas no sentido de reduzir a fragmentação característica de um currículo totalmente disciplinar e possibilitando uma redefinição quanto à forma como a seleção e organização de conteúdos e a definição de metodologias que vinham sendo efetuados nas escolas [...]. (OLIVEIRA E SILVA, 2013, p. 245)

Para Paulo Freire (1996), algo só é realmente aprendido se o aluno for capaz de recriar, de refazer o ensinado, estimulando a curiosidade epistemológica. "Neste caso, é a força criadora do aprender de que fazem parte a comparação, a repetição, a constatação, a dúvida rebelde, a curiosidade não facilmente satisfeita, que supera os efeitos negativos do falso ensinar [...]". (FREIRE, 1996, p. 25)

Os alunos foram desafiados nesse projeto a compreenderem a importância da história para suas formações humana e profissional. Mas há que se considerar que, a própria Maria afirma que ainda prevalece em sua orientação didática a perspectiva linear tão fortemente arraigada ao processo de difusão e apropriação do conhecimento histórico. Esse é um tema salutar para as discussões curriculares, pois não é possível pensar a história sem falar em cronologia.

O currículo estabeleceu uma confusão quando tomou o tempo sob vários enfoques, o que evidentemente reflete em uma não-estruturação consistente dos conteúdos. Se parte do pressuposto de que é possível trabalhar os conteúdos a partir de várias acepções de tempo, é preciso também demonstrá-lo através de uma lógica convincente. Na medida em que se considera como tempo o elemento fundamental para análise das sucessões e transformações que ocorreram numa determinada sociedade (através da linha do tempo) e a História como a disciplina responsável por situar o aluno diante das permanências e rupturas, ficamos frente a frente com o grupo dos Annales, no qual se inspirou o currículo. Marc Bloch na obra Introdução à História, referindo-se ao tempo histórico e à História como ciência, afirmou: ciência dos homens no tempo. O historiador não pensa apenas o humano. A atmosfera em que seu pensamento respira naturalmente é a categoria da duração [...] o tempo da história é o próprio plasma em que se banham os fenômenos, é como que o lugar de sua inteligibilidade [...]. (HORN, GERMANI, 2009, p. 50)

Desta forma, a noção de tempo cronológico tem sido a base para os currículos de história. Destacamos, porém, a tendência em se trabalhar com a concepção unilateral do tempo tanto no currículo formal, quanto no currículo praticado, deixando em defasagem as concepções de simultaneidade e multilinearidade. 
Analisando o discurso dos três docentes percebemos o quanto a linearidade ainda é forte influenciadora da organização curricular formal e das práticas pedagógicas. Dentre eles, apenas o professor Anísio afirmou trabalhar numa perspectiva de tempo cíclico, combatendo a linearidade. Enquanto que Maria e Darcy afirmaram categoricamente que ainda seguiam a lógica do tempo linear. Tal questão assim foi abordada na fala do professor Darcy:

\begin{abstract}
O nosso currículo antigo trabalhava a perspectiva de cronologia muito próxima à dos livros didáticos mesmo. Embora a gente faça relação com diferentes momentos da história, havia sim uma tendência, por mais que tentássemos em nosso trabalho de grupo e nas individualidades também, tentar fugir dessa linearidade, a gente percebia que no geral acabávamos ainda muito presos a questão da história nessa perspectiva cronológica, até porque o nosso programa estava organizado dessa forma: história antiga, a historia medieval, história moderna e história contemporânea [...]. (PROFESSOR DARCY. Depoimento [Agosto de 2014]. Entrevistadora Aline Cristina da Silva Lima. Natal, 2014. Gravador formato MP3. Entrevista concedida à pesquisa sobre práticas pedagógicas dos professores de História que atuaram entre os anos de 2005-2011 no Curso Técnico de Nível Médio Integrado de Turismo)
\end{abstract}

Esses docentes colocaram as influências externas ao currículo e as práticas que tendem a levá-los a manutenção da cronologia linear. Assim, pressões sociais para ingresso nas universidades, o caráter propedêutico do ensino, que Maria elucida como um aspecto que muitas vezes a levava a reproduzir os discursos de cursinhos ${ }^{5}$.

Notadamente, há uma influência do currículo formal sobre as práticas docentes, que no geral sofrem mudanças mais lentas que no âmbito da pesquisa. Há ainda um fator preponderante que é essa lógica francesa de organização do conhecimento escolar ser presente também nos cursos de formação de professores no contexto de formação dos sujeitos da pesquisa, "Essa divisão é a que prevalece nos cursos de História [...] e que se tem mantido desde a reformulação decorrente da Lei de Diretrizes e Bases de 1962, quando foi estabelecido o currículo mínimo pelo Conselho Federal de Educação [...]". (BITTENCOURT, 2009, p. 48)

E como esse aspecto curricular esteve relacionado às transformações no âmbito da EP? Discutimos na primeira seção desse trabalho a implantação do Decreto n. 5.154/2004, que corroborou para a organização do currículo integrado no CEFET/RN no ano de 2005. Quando questionamos o professor Darcy sobre essas mudanças ele assim reagiu:

Quando a nova lei (Decreto n. 5.154/2004), que a gente volta a trabalhar na
perspectiva da integração, a gente respirou aliviado e voltou a trabalhar numa
perspectiva que tínhamos antes [...]. Ao voltar o modelo da integração, a gente
passa por outra reformulação curricular, por um novo PPP a gente vai construir
outro currículo de História para os cursos, dessa vez com a opção temática, com a
realidade um pouco mais adaptada para o tema, essa questão do mundo do
trabalho, da história da técnica, mas, muitas dificuldades ainda são muito fortes
[...] eu ainda estou trabalhando com o currículo anterior [...]. (PROFESSOR DARCY.
Depoimento [Agosto de 2014]. Entrevistadora Aline Cristina da Silva Lima. Natal,
2014. Gravador formato MP3. Entrevista concedida à pesquisa sobre práticas

\footnotetext{
${ }^{5}$ Entende-se como "discurso de cursinhos" o estudo de todo conteúdo que era cobrado nos vestibulares, de modo a reproduzir o mecanicismo nos processos de ensino-aprendizagem.
} 
pedagógicas dos professores de História que atuaram entre os anos de 2005-2011 no Curso Técnico de Nível Médio Integrado de Turismo)

A discussão que o mesmo realizou nesse trecho da entrevista, nos aponta os meandros da vivência docente em meio às mudanças das políticas públicas para a EP, sobretudo nos anos 2000 . Sobre tais mudanças assim nos afirma Moura:

\begin{abstract}
Apesar dessas dificuldades, no início dos anos 2000, a conjuntura política permitiu retomar a discussão sobre a relação entre a educação básica, principalmente o ensino médio, e a educação profissional. Assim sendo, os autores mencionados anteriormente produziram reflexões importantes quanto à possibilidade de implementação plena da politecnia de forma universalizada no EM brasileiro nas condições socioeconômicas vigentes. Tais ponderações e análises permitiram concluir que as características atuais da sociedade dificultam tal implementação. Em primeiro lugar, o modo de produção capitalista tem como alimento vital a separação entre trabalho intelectual e trabalho manual, com a valorização do primeiro em detrimento do segundo, por meio da divisão social e técnica do trabalho que, dessa forma, viabiliza a reprodução ampliada do capital. Logo, só é possível pensar em politecnia e em escola unitária em seus sentidos plenos e para todos em uma perspectiva de futuro em uma sociedade em que a classe trabalhadora tenha conquistado o poder político e a burguesia tenha sido superada. (MOURA, 2013, p. 4)
\end{abstract}

A dicotomia, discutida por Moura, esteve também presente no diálogo com os docentes, estes afirmaram que havia um processo de luta no âmbito do currículo para se manter a carga horária da história, em meio a uma mentalidade arraigada ao tecnicismo. Analisando as falas dos professores sobre a relação Educação/trabalho, que não alcança a concepção de escola unitária defendida por Gramsci, percebemos que as visões variam muito e são um pouco superficiais quanto à compreensão do trabalho em suas diferentes dimensões, assim como em sua relação com o Ensino de História.

Chama-nos atenção ao fato de se sobrepujar o denominado núcleo da formação profissional em detrimento do núcleo geral, que comumente assumia o caráter de formação propedêutica. Este fato acentua a dicotomia, haja vista que configura uma espécie de junção e separação do ensino médio e educação profissional no contexto do EMI que legalmente era integrado, mas na prática prevalecia a separação.

O Ensino Médio Integrado, segundo Araújo (2013), foi um projeto em disputa com a pedagogia das competências, para tanto Ensino Integrado vai além do currículo integrado, posto que tem como premissa o diálogo, a formação inteira.

Nesse sentido, é salutar a necessidade de análise das práticas pedagógicas no interior do EMI para identificarmos se realmente ocorreu esse diálogo. Entendendo prática pedagógica como uma ação orientada, que tem como pressuposto o currículo formal, mas não é um reflexo do mesmo. Nem tampouco, existe uma fórmula que defina e limite o que são práticas pedagógicas em Educação Profissional. 


\section{CONSIDERAÇÕES FINAIS}

O trabalho é um pressuposto básico para a sobrevivência humana, e por isso mesmo está imerso no universo cultural, social e político dos sujeitos. Pode servir ou não, ao projeto de sociedade com o qual dialoga, podendo ser socialmente útil e humanizador ou, ser objeto de desantropomorfização e alienação. Uma educação que permite a inserção do trabalho como princípio educativo, em suas dimensões ontológicas, históricas e sociais. Concebendo, portanto, o trabalho para além dos interesses do capital, precisa, pois, ter como preâmbulo a superação da dualidade educacional. Educar para a emancipação.

Consideramos uma educação emancipatória a que permite o desenvolvimento das capacidades críticas e do saber fazer, em um processo de compreensão de que toda ação humana é prática, mas é também planejada e associada ao pensamento, embora muitas vezes não crítica. Associar essas dimensões numa perspectiva de formação humana integral é um desafio para o contexto atual, e mais ainda para os primeiros anos de vivência do projeto de Ensino Médio Integrado, como é o caso de nossa pesquisa (2005-2011).

Identificamos nas narrativas dos sujeitos, as inquietações frente à nova proposta de integração, legitimada pelo Decreto n. 5.154/04, o qual permitia a oferta de Ensino Médio integrado a Educação Profissional. Essa mudança, que em si já era complexa, possuía uma particularidade: os professores não tiveram, em sua formação, as bases para atuação no EMI. A postura da instituição em assumir o EMI, exigia a construção de um novo PPP e de novos projetos de curso, que se adequassem a tal realidade.

Diante disso, cada docente criou sua própria estratégia para atuar de modo mais significativo naquele contexto. Em seus discursos ficava clara a intenção de formar os educandos para além da técnica, elucidando a expressão do professor Darcy, era uma espécie de formação do técnico cidadão. A tônica era de formar para o trabalho, finalidade do então CEFET/RN, mas ao mesmo tempo problematizar esse universo e colocar em pauta as demais dimensões do ser humano: a cultura, a ciência e a tecnologia. A questão é que o discurso parecia apontar para a essência do EMI, enquanto as práticas divergiam, sinalizando uma permanência de um currículo unilateral, e especificamente no caso da História, centrado na formação propedêutica. Percebemos que as prescrições curriculares não são garantia de práticas pedagógicas efetivamente integradoras.

O Projeto Pedagógico de Curso - Turismo (2005) já trazia em si uma problemática frente ao ensino integrador: a elucidação do tema trabalho somente em algumas disciplinas, como no caso da História. Correndo-se o risco de resumi-lo apenas a formação técnica, ligada ao núcleo da formação profissional, fator que criava dentro do próprio currículo uma separação. Além disso, se expressava, outro tipo de fragmentação, relacionada a divisão da carga horária do curso: nos primeiros anos havia forte presença das disciplinas do núcleo comum em detrimento da parte diversificada e da formação profissional, questão que foi posta pelos estudantes como se nos primeiros anos fosse uma formação propedêutica e, nos últimos, a formação profissional.

A despeito das fragilidades expressas no currículo do curso Integrado de Turismo, existiam práticas que fugiam as prescrições e conseguiam associar as diferentes dimensões do trabalho, social, histórica e ontológica. Como no caso do projeto Meu Curso e a História, no qual a professora Maria, direcionou o Ensino de História numa perspectiva temporal menos factual e linear, 
problematizando a vivência direta dos estudantes, sua profissionalização e o mundo do trabalho. Tal experiência demonstrou que é possível desenvolver práticas mais aproximadas do currículo integrador. No entanto, dada as especificidades e as exigências de associação entre o domínio conceitual da História, da pedagogia e da relação educação/trabalho, essas ações não se tornaram rotina no âmbito escolar.

O EMI pressupõe uma integração orgânica, para além da prática disciplinar e interdisciplinar. O que indica a necessidade de reflexão e produção do conhecimento nessa área, bem como a formação de professores mais direcionada para tal realidade. Daí a importância de termos no Brasil um programa de pós-graduação que se propõe a estudar e problematizar a Educação Profissional, e aos poucos atender as demandas para essa área. Incitando a produção de novos saberes em EP e instigando-nos a pensar novas proposições teóricas e práticas.

Diante do exposto anteriormente chegamos a conclusão de que não havia no universo do EMI, especificamente no recorte espaço-temporal a que nos reportamos um único modelo de prática pedagógica no Ensino de História. Por razões que parecem óbvias: os sujeitos são historicamente construídos, suas concepções de mundo incidiam em suas práticas; havia um processo inconcluso de transformação do Ensino de História e o âmbito da Educação Profissional e Ensino Médio Integrado ainda não amadureceram no espaço da produção do conhecimento, especialmente na conexão entre essas dimensões e o Ensino de História.

\section{REFERÊNCIAS}

1. ARAÚJO, Ronaldo M. de Lima. Práticas Pedagógicas e Ensino Integrado. 36a Reunião Nacional da ANPED, Goiânia, 2013. Disponível em: <http:// http://36reuniao.anped.org.br/pdfs_traba Ihos_aprovados/gt09_trabalhos_pdfs/gt09_3041_texto.pdf >. Acesso em: 20 ago. 2014.

2. BEZERRA, Luzia Freire da $C$. As bases da industrialização brasileira à época do desenvolvimento do ensino técnico. In: PEGADO, Erika Araújo da Cunha (Org.). A trajetória do CEFET-RN desde a sua criação no início do século XX ao alvorecer do século XXI. 2. ed. Natal: IFRN, 2010. p. 15-30.

3. BITTENCOURT, Circe M. Fernandes. Capitalismo e cidadania nas atuais propostas curriculares de História. In:_BITTENCOURT, Circe M. Fernandes (Org.). O saber histórico na sala de aula. 12 ed. São Paulo: Contexto, 2013.

4. BRASIL, Decreto n. 5.154/04 - Regulamenta o § 20 do art. 36 e os arts. 39 a 41 da Lei no 9.394, de 20 de dezembro de 1996, que estabelece as diretrizes e bases da educação nacional, e dá outras providências. Disponível em <http://portal.mec.gov.br/setec/arquivos/pdf1/proejade creto5154.pdf>. Acessado em: 10 set. 2013.

5. BRASIL. Curso Técnico de Nível Médio Integrado - Turismo: Plano de Curso. Autorizado pela Resolução № 05/2005-CD-CEFET-RN. Disponível no arquivo eletrônico institucional do IFRN Campus Cidade Alta.

6. BRASIL. Educação Profissional Técnica de nível médio integrada ao Ensino Médio: Documento Base. Brasília, 2007b. Disponível em: <http://portal.mec.gov.br/setec/arquivos/ pdf/documento_base.pdf $>$. Acesso em: 3 jun. 2010.

7. FONSECA, Selva G. Didática e prática de ensino de História: experiências, reflexões e aprendizados. Campinas: Papirus, 2003. 
8. FREIRE, Paulo. Pedagogia da Autonomia: saberes necessários à prática educativa. São Paulo: Paz e Terra, 1996. (Coleção Leitura).

9. GRAMSCI, Antonio. Os intelectuais e a organização da cultura. São Paulo: Cortez, 1991.

10. HORN, Geraldo B; GERMINARI, Geyso D. O ensino de história e seu currículo: teoria e método. 2 ed. Petrópolis, RJ: Vozes, 2009.

11. MACHADO, Lucília Regina de Souza. Ensino médio e técnico com currículos integrados: propostas de ação didática para uma relação não fantasiosa. In: MOLL, Jaqueline et al (Org.). Educação Profissional e tecnológica no Brasil contemporâneo: Desafios, tensões e possibilidades. Porto Alegre, RS: ARTMED, 2009.

12. MONASTA, Attilio. Antonio Gramsci. Recife: Fundação Joaquim Nabuco. Editora Massangana, 2010. Tradução: Paolo Nosella.

13. MONTEIRO, Ana Maria F. C. Professores de História: entre saberes e práticas. Rio de Janeiro: Mauad X, 2007.

14. NÓVOA, António. Diz-me como ensinas, dirte-ei quem és e vice-versa. In: FAZENDA, Ivani C. A. (Org.). A pesquisa em educação e as transformações do conhecimento. 2. ed. Campinas, SP: Papirus, 1997.

15. OLIVEIRA E SILVA, Miriam S. de. Meu Curso e a história: a interdisciplinaridade no curso técnico integrado do Instituto Federal de Educação, Ciência e Tecnologia do Rio Grande do Norte. Holos, Natal, ano 29, v. 1, 2013. Disponível em: <http://www2.ifrn.edu.br/ojs/index.php/HO LOS/article/view/850/654>. Acesso em: 20 ago. 2014.

16. PINSKY, Jaime; PINSKY, Carla. O que e como ensinar - Por uma História prazerosa e conseqüente. In: KARNAL, Leandro (Org.). História na sala de aula: conceitos, práticas e propostas. 6 ed. São Paulo: Contexto, 2010, p. 17-48.

17. RAMOS, Marise. Ensino Médio Integrado: ciência, trabalho e cultura na relação Educação Profissional e Educação Básica. In: MOLL, Jaqueline e Colaboradores. (Org.). Educação profissional e tecnológica no Brasil contemporâneo: Desafios, tensões e possibilidades. Porto Alegre, RS: Artmed Editora, 2008. p. 38-54. 